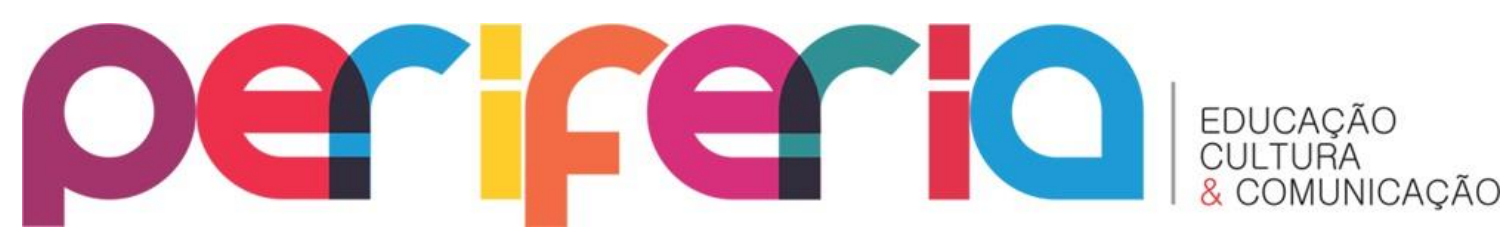

DOI: $10.12957 /$ periferia.2019.30975

\title{
UM OLHAR SOBRE O PROCESSO DE SUBJETIVAÇÃO DO MC TS: A FAVELA, O FLUXO E (EST)ÉTICA DO CONSUMO
}

\author{
João Augusto Neves ${ }^{1}$ \\ Universidade Estadual de Campinas - UNICAMP
}

\section{Resumo}

Durante as entrevistas realizadas para a produção do documentário "É o fluxo" alguns personagens se tornaram emblemáticos devida à riqueza de detalhes apresentados em sua narrativa. Por meio dos encontros proporcionados no decorrer das filmagens e através do compartilhamento de imagens e materiais sonoros e poéticos, alguns elementos provocaram a reflexão sobre questões relativas aos processos de subjetivação na sociedade contemporânea. Com isso em mãos, enumerei algumas análises possíveis sobre a cultura funk, a favela e a (est)ética do consumo.

Palavras-chave: subjetividades; cultura Funk; sociedade do consumo

\footnotetext{
${ }^{1}$ Doutorando em História na Universidade Estadual de Campinas. Graduado e Mestre em História pela Universidade Federal de Uberlândia, onde também desenvolveu projetos de pesquisa, ensino e extensão ligados às temáticas: Artes, Tecnologias digitais, Educação e Culturas Populares. prof.joaoneves@gmail.com
} 


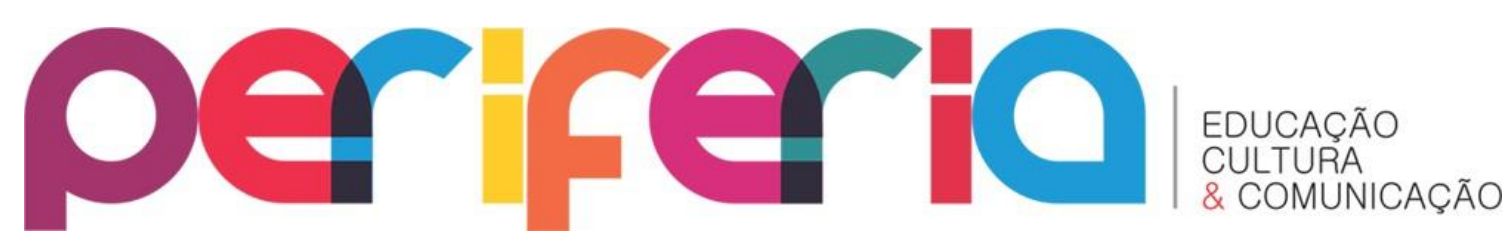

DOI: $10.12957 /$ periferia.2019.30975

\title{
A VIEW ABOUT THE SUBJECTIVATION PROCESS OF MC TS: THE “FAVELA”, THE FLOW AND THE (AESTH)ETHIC OF CONSUMPTION
}

\begin{abstract}
In the course of the interviews made for the documentary "É o fluxo" some characters have become emblematic due to the richness of details presented in their narratives. Through the meetings provided during the filming and the sharing image, sound and poetic materials, a few elements did to think about issues related to the processes of subjectivation in contemporary society. Thereafter, l've pointed some reviews about the funk culture, the shanty town and the (aesth)ethics of consumption.
\end{abstract}

Keywords: Subjectivist; Funk culture; Consumer Society. 


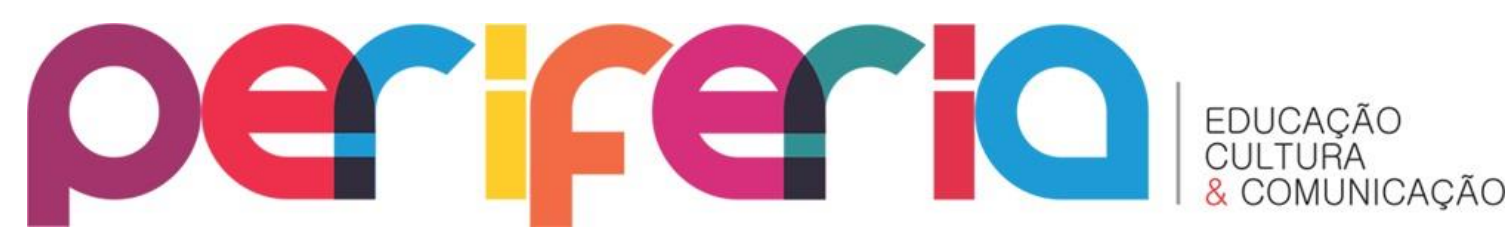

DOI: $10.12957 /$ periferia.2019.30975

Mateus Xavier Martins, de 17 anos, migrou da pequena cidade de Canápolis/MG, interior do triângulo mineiro, para a Uberlândia com 13 anos de idade. Parte de sua família já estava residindo nessa cidade de médio porte, algo que facilitou sua decisão de deixar a casa do pai e madrasta para ir morar com mãe e irmãos na periferia de Uberlândia. Todo esse processo é bastante conturbado, a saída da casa do pai e a vinda para casa da mãe se dá entre conflitos familiares, dificuldades financeiras e questões que impactaram de forma decisiva no processo de educação e amadurecimento daquele menino. Durante entrevista concedida ao autor deste artigo, as referências a esse passado provocavam certo desconforto em Mateus, fazendo vir à tona lembranças de momentos de grande conturbação sofridos na infância e adolescência. “Minha infância? Vixe, foi uma loucura”, revela o jovem. Entre os breves relatos de meninice aparecia em sua fala situações traumáticas de sua formação.

No dia em que foi entrevistado ${ }^{2}$ Mateus morava no bairro Dom Almir ${ }^{3}$, na casa de um amigo, e era conhecido no bairro por Mc TS - ou TEÉSE como ele escrevia em seu perfil de Facebook. Esse personagem surge, conforme indica durante nossa conversa, das rodas de improvisação de rap e funk e nos espaços dos bailes na região que residia. "Ter muito dinheiro" e “muitos acessos" em seus vídeos e perfil do Facebook eram seus maiores sonhos. Histórias como essa se repetiram - e ainda se repetem - no decorrer das primeiras décadas do século XXI nas periferias de várias

2 Os relatos citados no decorrer deste texto correspondem ao acervo de material audiovisual coletado durante a produção do documentário É o fluxo (2015). XAVIER, Mateus (MC TS). É o fluxo. Entrevistador: João Augusto Neves; Roberto Camargos. Uberlândia: Centelhafilmes, Agosto de 2014. Entrevista concedida para o documentário "É o fluxo".

3 O bairro Dom Almir e seus vizinhos Celebridade, Prosperidade e Morumbi, localizados na Zona Leste da cidade de Uberlândia/MG, que ganharam o enfoque neste artigo, têm um histórico peculiar por terem surgido, no final dos anos de 1990 e começo de 2000, em função de financiamentos do poder público para construção de conjuntos habitacionais em lugares com presença de ocupações urbanas e destinados às famílias de baixa renda, em um contexto de forte especulação imobiliária na cidade. Concentram, desde sua criação, uma população de perfil socioeconômico desfavorável, "predominando no local os grupos de baixa renda, um comércio insipiente e uma carência de equipamentos públicos”. Essa região, desde seu surgimento, explicita o descaso do poder público, um lugar com poucas áreas de lazer e com altos índices de violência, agravados com a presença de dois centros de detenção em suas proximidades e outros bairros irregulares (áreas de ocupação).

Periferia, v. 11, n. 1, p. 260-278, jan./abr. 2019 

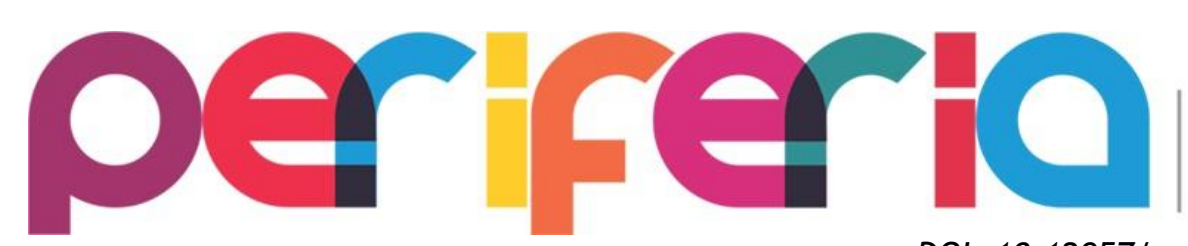

DOI: $10.12957 /$ periferia.2019.30975 cidades brasileiras, por isso, a sua escolha para as reflexões que serão desenvolvidas ao longo desse artigo.

O que se tentará elucidar, por meio da história de Mateus e de seu personagem Mc TS, é a maneira pela qual ocorre o processo de subjetivação destes jovens que viviam nas periferias urbanas, que estavam conectados à internet, eram consumidores e produtores de música funk e, de alguma maneira, (re)produziam a cultura do luxo e da ostentação dos bens materiais de consumo de massa característicos do capitalismo contemporâneo.

Mateus exemplifica uma prática que vários adolescentes pobres, próximos as práticas circunscrita à cultura funk, vinham adotando - principalmente a partir das primeiras décadas do século XXI - em diferentes lugares do país, mudando as pautas do noticiário tradicional e despertando atenção por protagonizarem atividades que não estavam circunscritas à violência e criminalidade. Entre as práticas desenvolvidas por esses jovens, víamos, por exemplo, no decorrer dos anos de 2010, os "rolezinhos" nos shoppings, as famosas danças do romano e do passinho e as publicações e edições de fotos e vídeos em redes sociais como o Facebook. ${ }^{4}$ Neste caso em específico, tais instrumentais eram utilizados, muita das vezes, por esses sujeitos como estratagemas para sair do anonimato, arregimentar um grande número de visualizações e seguidores e aumentar o seu capital simbólico junto ao público do universo funk. ${ }^{5}$ Ou seja, essas manifestações culturais e sociais expressam um vocabulário simbólico produzido e difundido no âmbito da sociedade do consumo, cujo objetivo prioritário era alcançar a inserção nessa mesma sociedade. Isso pode ser percebido - conforme analisarei no decorrer deste texto - com maior nitidez,

$4 \quad$ Sobre as práticas dos rolezinhos e a cultura digital que envolve essas ações ver: CALDEIRA, Teresa Pires do Rio Caldeira. Qual a novidade dos rolezinhos? Espaço público, desigualdade e mudança em São Paulo. Novos Estudos. CEBRAP, n 98. pp. 13-20, Março 2014.

$5 \quad$ As práticas assinaladas no texto são protagonizados, em sua maioria, por jovens moradores da periferia e representam o uso do vocabulário simbólico da sociedade do consumo para acessar a sociedade contemporânea. O que vem chamando a atenção de intelectuais e jornalistas é a maneira como estas manifestações têm ganhado força e como são organizadas a partir das redes sociais da internet. No entanto, creio que ainda é necessário aprofundar as pesquisas em cada uma destas práticas e tentar compreender suas origens, motivações e consequências. Neste texto pretendo me debruçar não em uma prática específica, mas na história de um jovem que está submerso na cultura funk e na cultura digital, as quais dão subsídios simbólicos a todas estas manifestações. Desta forma, penso que ao olhar para Mateus, acabo também abrindo frentes de debates que alcançam as realidades destas práticas culturais e dos sujeitos que nelas estão envolvidos.

Periferia, v.11, n. 1, p. 260-278, jan./abr. 2019 

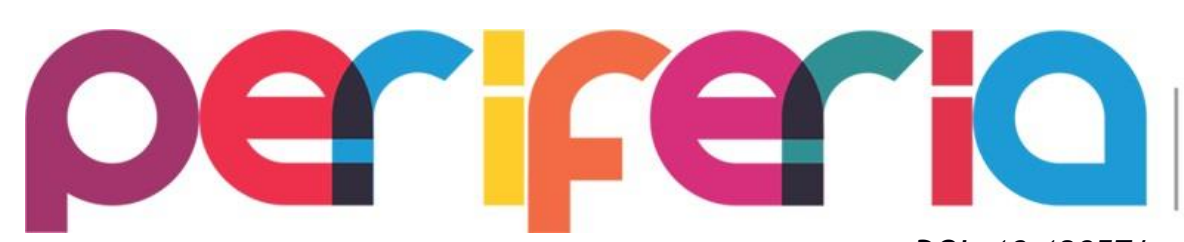

EDUCAÇÃO

CULTURA

\& COMUNICAÇÃO

DOI: $10.12957 /$ periferia.2019.30975

quando atentamos para os discursos presentes nas músicas que Mateus compõe, nas performances poéticas e corporais que formam o artista/personagem do MC TS e nas experiências somadas no decurso de sua vida.

Portanto, farei alguns apontamentos e novas perguntas sobre sentimentos, sensibilidades e subjetividades de jovens pobres moradores da periferia na sociedade contemporânea a partir deste mergulho na história de Mateus. Entrecruzando com outras histórias de Mc's da região que ele vive e com as dos Mc's que conseguiram visibilidade na mídia tradicional e possuíam status no mundo do funk, pretendo ilustrar as subjetividades dos jovens que queriam se conectar, e se conectavam de alguma maneira ao mundo globalizado.

Diante disso, cabem algumas indagações: como estes jovens que viviam em bairros pobres, com pouca infraestrutura, com baixos níveis educacionais e com pouco acesso a múltiplos bens culturais assimilavam e organizavam - poética e esteticamente - uma vida baseada no luxo e na ostentação? E quais dispositivos eram por eles acionados para se conectarem a essa sociedade objetivando a sua inserção? Nesse terreno controvertido e de respostas divergentes, alguns os colocariam como revolucionários, outros como alienados. Da parte do autor deste artigo, há a compreensão de que é necessário ir mais a fundo na discussão, acreditando que o processo de subjetivação desses jovens pode ser uma luz que ajuda a clarear as escolhas e os caminhos por eles trilhados.

Para determinadas leituras midiáticas, o que esses jovens fazem é "um teatro contemporâneo para os desprivilegiados, que interpretam inversões de status e hierarquias, invertendo e subvertendo o script dominante" (LEMOS, 2012). Arriscome a dizer que tais manifestações, talvez, não tenham um significado tão especial assim, mas somente apresentam a maneira pela qual as classes populares leem, interpretam a contemporaneidade e, a partir disso, se colocam no jogo do dia a dia. Pode ser até que elas "invertam o script dominante", mas, na maioria das vezes, o que se observa no caso destes jovens da periferia que ressignificavam as "performances da ostentação" inscritas no mundo funk é a apropriação de aspectos perversos da sociedade capitalista. 0 consumo, o luxo e a ostentação tornaram-se os pilares que sustentavam a maneira de estar no mundo, bem como representavam as 


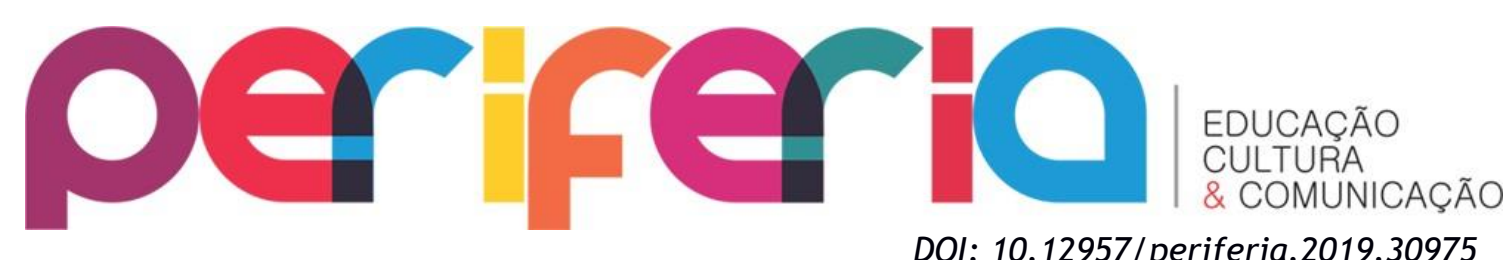
vias de acesso para a sociedade globalizada. Bauman (2013), coloca que isso se torna cada dia mais presente

graças à rede de "autoestradas da informação", em rápido crescimento tanto em extensão quanto em densidade, todo e qualquer indivíduo (homem ou mulher, adulto ou criança, rico ou pobre) é convidado, tentado e induzido (ou seja, compelido) a comparar sua própria sorte com a de todos os outros; em particular, com o consumo excessivo praticado pelos ídolos públicos (celebridades constantemente expostas nas telas de TV e nas capas de tabloides e revistas de luxo); e mensurar os valores que tornam a vida digna de ser vivida pela opulência que eles exibem. (BAUMAN, 2013, p. 27)

Quer dizer, as falas e composições de Mateus, a exemplo de várias manifestações de jovens que incorporam a lógica da ostentação de dinheiro, carros, motos, enfim, do poder material e financeiro, são subsidiados por este contexto apresentado por Bauman no qual a "vida é digna de ser vivida" a partir do momento que o sujeito consegue ter e ostentar os símbolos e bens materiais da sociedade do consumo de massa.

\section{2}

Uma vez instalado em Uberlândia, Mateus iniciou suas atividades como cantor e compositor tendo como referência os artistas do mundo funk e os outros jovens que conheceu no bairro Dom Almir. Nas praças e nas ruas, nos momentos de lazer e nos encontros, foi a batida do funk que o ajudou a criar os elos de aproximação e trocas de experiências. Compondo, ouvindo músicas no "radinho"6, improvisando, assistindo vídeos e trocando informações sobre o universo cultural que partilhavam, esses jovens alimentavam sonhos, apropriavam-se dos códigos e linguagens que circulam em seu meio social e faziam uso dos referenciais acessados para, de alguma maneira, participarem do mundo que os rodeava. Ser Mc, aprender a improvisar e compor músicas naquele espaço do bairro significava muito para Mateus e seus amigos. Essa questão fica bastante evidente na fala de Mc Vó, uma jovem moradora das mediações: "Nois começamos, tipo aqui nessa casa aqui brincando. De amigo que fazia a barulhada mesmo, cantando. Até que um deu certo e começou a levar a

$6 \quad$ Nome dado aos aparelhos celulares.

Periferia, v. 11, n. 1, p. 260-278, jan./abr. 2019 

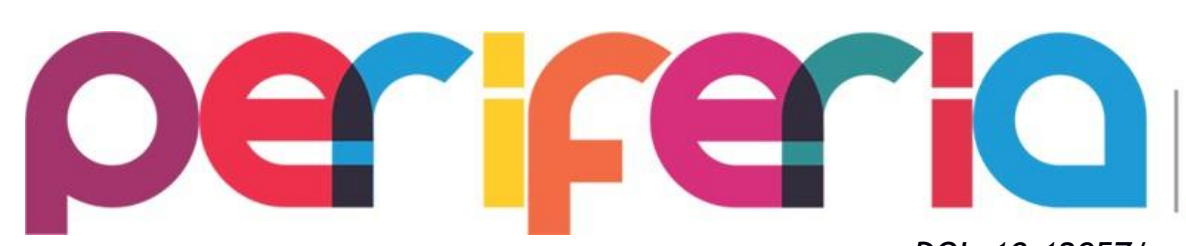

EDUCAÇÃO

CULTURA

\& COMUNICAÇÃO

DOI: $10.12957 /$ periferia.2019.30975

diante. Aí, uns começaram, aí já estão mais para frente e nois tá aqui começando de novo". ${ }^{7}$

Imitando os artistas e cantando as músicas de gosto comum, eles intensificavam os relacionamentos, teciam suas redes de amizade e construíam suas próprias identidades. A expressão "um deu certo e começou a levar a diante", se refere àqueles que se assumiram como Mc's, que foram "batizados" com um nome artístico - Mc Tomate, Mc TS, Mc Menor, Mc Vitinho, Mc Nael, para citar alguns -, investiram nessa nova identidade e nas estratégias performáticas que estão por detrás deste personagem.

Se compreendermos, como Seixas, que na modernidade "o homem é, portanto, no meio do mundo, uma criatura múltipla e multifacetada" (SEIXAS, 2012, p.282), estes jovens, partilhando este recurso do projeto moderno, (re)criavam constantemente suas identidades "e, a partir desse movimento de extroversão e atuação no e sobre o 'mundo circundante', elaboravam, experimentavam, imaginavam e fabricavam concomitantemente seu 'mundo interior' digamos, valendo-se da noção a nós contemporânea, a sua subjetividade, o seu Eu" (IBID, p.280). Nestes espaços e nestas brincadeiras surgiram aqueles que aprenderam a dançar, os que fazem o beat box, os que rimam, aqueles que desenham e os cantores da turma. Da mesma forma que seus amigos, Mateus teceu sua identidade em torno da vontade de ser o MC TS e a partir daí seus sonhos, angustias, bem como as estratégias de ser e de agir na sociedade eram interpretados por esta "persona". 0 Mc TS the possibilitara entrar nos bailes sem pagar ingresso, adquirir respeito e confiança entre os amigos e, em certa medida, ganhar notoriedade entre algumas pessoas que circulavam pelos mesmos espaços. Claro que esta rede era muito restrita, que os elos eram frouxos e que este personagem era instável e com poucas garantias de se manter firme. Entretanto, em vários momentos ele era acionado e funcionava como um passaporte para que o ator - Mateus - conquistasse, de alguma

7 FHOSTTHER, Vitoria Gabriela (Mc Vó). É o fluxo. Entrevistador: João Augusto Neves; Roberto Camargos. Uberlândia: Centelhafilmes, Agosto de 2014. Entrevista concedida para o documentário “É o fluxo".

Periferia, v. 11, n. 1, p. 260-278, jan./abr. 2019 

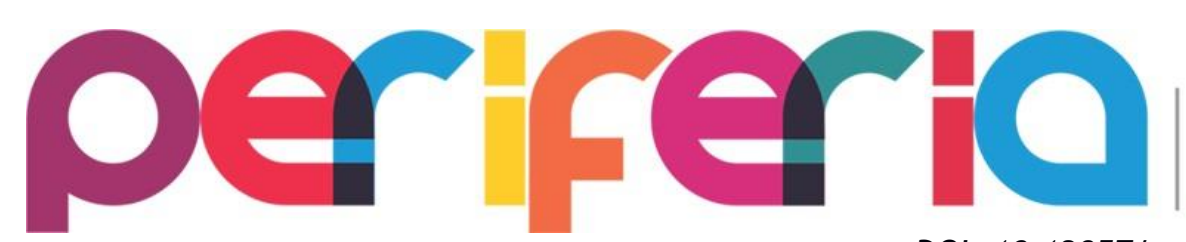

DOI: 10.12957/periferia.2019.30975 maneira, o que ele desejava: as curtidas no Facebook, a atenção dos amigos e familiares, o respeito no baile, a admiração.

Mateus contou que a gênese do seu personagem se deu

depois de dois meses, mais ou menos, que eu morava aqui. O Mc Maikera tava lá na praça mais o Menor do Charme. Aí eles cantando lá e eu só observando. Aí, eu: “Nó, eu não faço nada aqui!”. (...) Aí, o Maikera fez uma música. Aí eu falei: "Nó, como é que ele fez essa música?". (...) Aí, eu olhei assim: "Nossa, eu tenho o dom também, vou fazer uma música, vai que cola". Aí, foi onde eu fiz minha primeira música, "Nois é mil grau". Aí na hora que eu escrevi ela, eu falei: "vou mostrar para ele, se ele gostar eu vou virar MC". Aí eu cheguei mostrei para ele, aí ele: "Nó, pode crer, ficou boa". ${ }^{8}$

Como se nota, foi através da música funk que Mateus criou seus vínculos de amizade no bairro e a partir daí circulou com mais tranquilidade naquele espaço. ${ }^{9}$ Ao compreender os códigos culturais estabelecidos entre jovens do bairro, Mateus conseguiu acessar e circular pelo Dom Almir, tecer amizades e adquirir confiança. Ao acessar o bairro e usar os signos do lugar e dos sujeitos que ali habitavam, ele aprendeu as leis do território e buscou reconhecimento como Mc TS, pois o personagem precisava "colar". Ou seja, foi o funk, enquanto música, cultura e técnica compositiva, que possibilitou a sua aceitação e the proporcionou a ampliação de vínculos e possibilidades de ocupar determinados lugares, como por exemplo, os bailes, as rodas de improviso na praça, a casa de amigos, dentre outros.

Entretanto, em que pesem esses vários aspectos positivos no processo de socialização e inserção social do entrevistado, é necessário verificar, também, a face perversa desse mesmo processo de subjetivação. Nos diferentes momentos que este autor pode acompanhar as atividades desenvolvidas por Mateus - bailes funk, entrevista, gravação de sua música e até em sua casa com seus familiares -, notouse um sujeito se metamorfoseando em diferentes personagens, variando do menino

8 XAVIER, Mateus (MC TS). É o fluxo. Entrevistador: João Augusto Neves; Roberto Camargos. Uberlândia: Centelhafilmes, Agosto de 2014. Entrevista concedida para o documentário "É o fluxo".

9 Durante entrevista, Mateus relata que devido a fama, disseminada pela cidade de Uberlândia e da região, sobre a periferia, e principalmente o bairro Dom Almir, ele temia os perigos que the foram contados. Morte, tráfico de drogas e vadiagens na rua a todo instante eram alguns dos estigmas em torno do imaginário sobre o bairro. 0 entrevistado diz que apesar dos conflitos inerentes a bairros pobres da periferia, "maioria da galera é de boa e que não precisa ter medo de viver aqui”.

Periferia, v. 11, n. 1, p. 260-278, jan./abr. 2019 

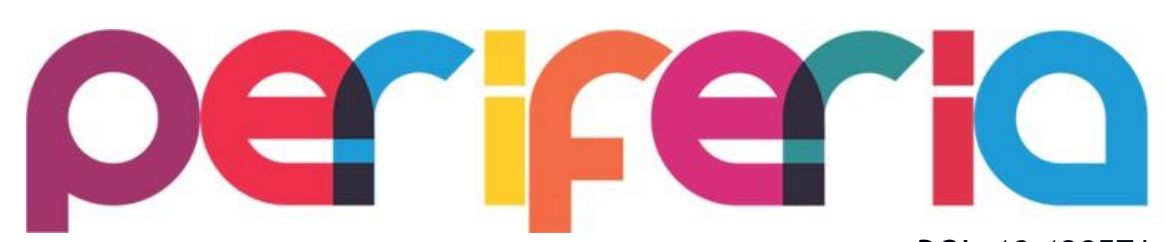

EDUCAÇÃO

CULTURA

\& COMUNICAÇÃO

DOI: $10.12957 /$ periferia.2019.30975

imaturo e brincalhão ao cantor Mc TS e se atrapalhando diante dos personagens que o atravessavam. Isso fica mais evidente quando se analisa o seu perfil no Facebook. $\mathrm{Ali}$, as diferentes personas por ele incorporadas se confundiam e entravam em conflito, ou, por vezes, se hibridizavam para dar sentidos ambíguos tanto para Mateus quanto para Mc TS.

\section{Imagem 01}

Mateus Martins adicionou uma nova foto.

21 de agosto - है

Tao .achando..q.e. so ..pega..o..microfone.e..canta.vaii..pençandoo áki.e esquisito kkk

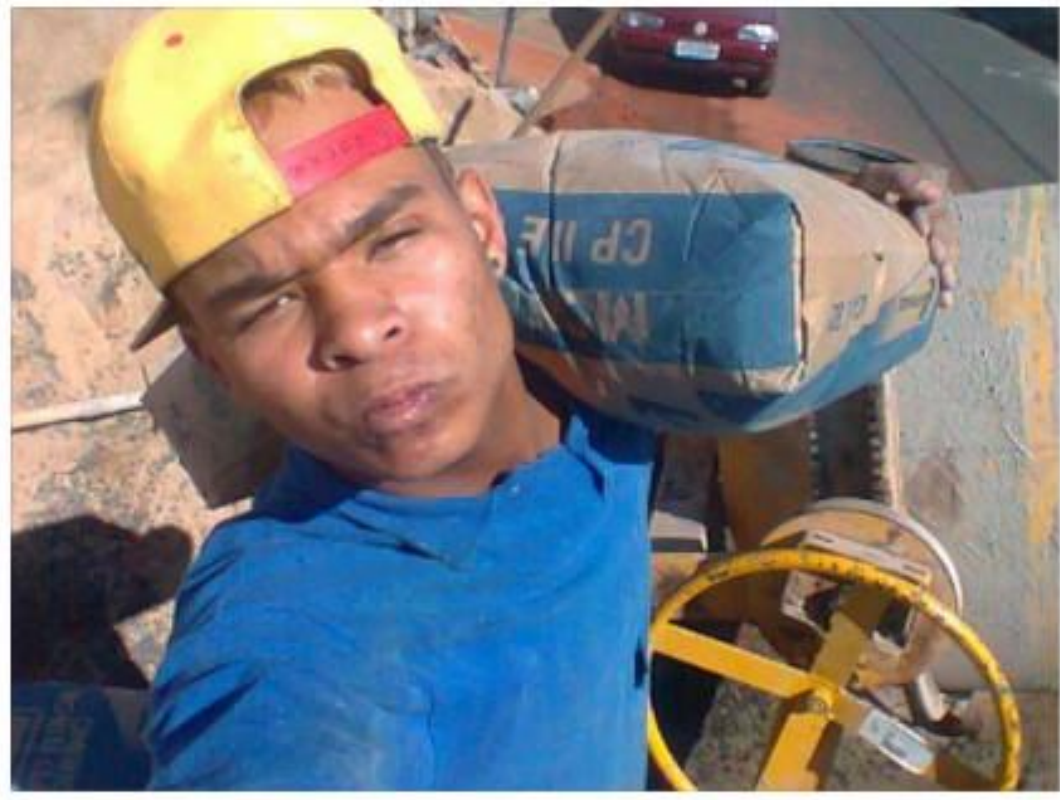

Descurtir Comentar Compartilhar

ß Você, Roberto Camargos e outras 16 pessoas curtiram isso.

\section{Edrielly Maria ate que fim kkkkkkk}

21 de agosto às $10: 52$. Curtir

Mateus Martins Nehhhh. kkkk

21 de agosto às 11:51 Curtir

Daniel Barbosa CHAMA A POLICIA !!!!!!!!!!!!!!

23 de agosto as 18:59 Curtir

Escreva um comentäio

FONTE: Print da página do Facebook de Mateus.

O que vemos na imagem? Mateus, Mc TS ou um trabalhador da construção civil? Quais personas foram acionadas e porque foram acionadas? Ao publicar/publicizar um dia de trabalho, Mateus mostra para amigos e familiares que estava trabalhando, Periferia, v. 11, n. 1, p. 260-278, jan./abr. 2019 

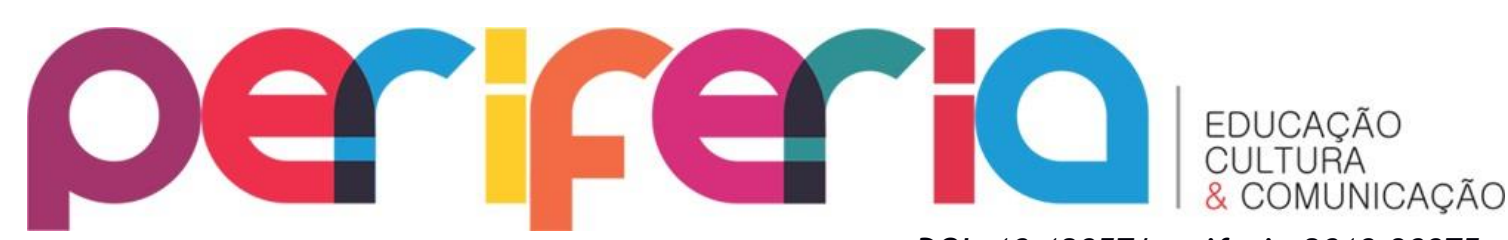

DOI: $10.12957 /$ periferia.2019.30975 estava longe da criminalidade e que conquistará seus sonhos com esforços. A crença e os créditos dados a ele valiam, no seu entendimento, a soma das 18 pessoas que curtiram a imagem/texto e os comentários - "Ate que fim kkkkkk". 0 texto que antecede a imagem traz outra informação, que remete ao Mc TS e nos explica o porquê de publicar tal foto. Mateus mostra a outra face de seu personagem e diz para aqueles que "estão achando que é só pega no microfone e cantar", que TS trabalha, e trabalha pesado carregando quilos de cimento nas costas, mas que se mantêm firme, pois "aqui é esquisito". Essa questão do trabalho reaparecia, diversas vezes, durante nossa entrevista. Certa vez ele contou: "Vixi, já trabalhei de tudo! De Tudo! Agora está difícil, mas tenho certeza que vai melhorar”. Ele entende, como aparece na narrativa dos seus ídolos do funk ${ }^{10}$, que o esforço, o trabalho difícil e as dificuldades da vida são parte da história de qualquer Mc que pretende o sucesso noções subjetivadas que ganhavam sentido na história de Mateus e do Mc TS. Percorrendo seu perfil no Facebook é possível notar que a cada troca de emprego, idas para bailes, selfies próximo a carros de luxo ou com roupas de alguma marca e dias de trabalho, este universo do Mateus e do Mc TS são colocados em destaque e usados para subsidiar suas personas e a narrativa de suas histórias.

10 O Jornal Folha de São Paulo, apresenta Mc Guimê, o maior ícone do estilo Funk Ostentação no país, como um jovem "que sonhava com carrões enquanto trabalhava em uma quitanda. Hoje além de automóveis, o dono de "país do futebol", hit não oficial da Copa, ostenta uma amizade com Neymar, música na abertura da novela da Rede Globo de Televisão e cadeira VIP na São Paulo Fashion Week." Durante a reportagem em vários momentos o histórico do menino pobre da periferia é ressaltado. O mesmo destaque é dado na revista Astros e Ídolos, a qual pontua que "Guimê sempre gostou de ostentar e ralava para isso: fazia bicos para faturar 80 reais no dia, caso dobrasse o turno, e gastava toda a grana em produtos que seu pai não podia dar - tênis, roupas e óculos de marca". Essas reportagens dão força a algo que já foi apropriado pelo personagem Guimê. Nos videoclipes e nas músicas este passado de trabalho e esforço é rememorado como glórias de um jovem que venceu na vida. A música "País do futebol" citada pela reportagem da Folha de São Paulo, contém estes elementos: "No flow, por onde a gente passa é show. Fechou, e olha onde a gente chegou (...) A rua é nossa e eu sempre fui dela. Desde descalço gastando canela, hoje no asfalto de toda São Paulo de nave do ano tô na passarela." Ver em: KUCHLER, Adriana. Amigo de Neymar, Mc Guimê fala de maconha, ostentação e seu hino da copa. Folha de São Paulo. São Paulo, p. 1-10. 29 jun. 2014. Disponível

em:<http://tools.folha.com.br/print?url=http://www1.folha.uol.com.br/serafina/2014/06/1476758 -amigo-de-neymar-mc-guime-fala-de-maconha-ostentacao-e-seu-hino-

dacopa.shtml\&site=emcimadahora>. Acesso em: 31 jul. 2014. ; ASTROS E ÍDOLOS: Mc Guimê o rei do Funk Ostentação. Bauru, São Paulo: Alto Astral, v. 65, n. 12, 2014.

Periferia, v.11, n.1, p. 260-278, jan./abr. 2019 

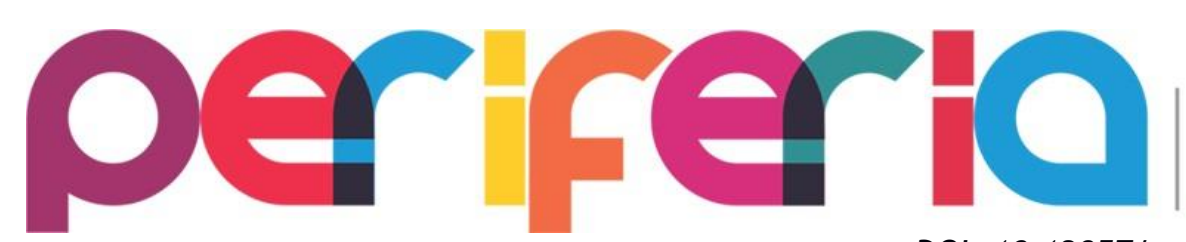

EDUCAÇÃO

CULTURA

\& COMUNICAÇÃO

DOI: 10.12957/periferia.2019.30975

Em outra interpretação das formas acionadas na imagem anterior poderíamos dizer que este é um jovem trabalhador da construção civil ${ }^{11}$ que sonha em ser cantor e que luta para alcançar seus objetivos. Texto e imagem se completavam e repetiam o que Mateus ressaltou durante a entrevista ao contar de outra experiência no mercado de trabalho: "Lá é molhado12. Ter que ficar lá! Mas tem que trampar! Porque sem trampo, né? Mas eu já passei por altos bagulho, eu nem esquento não. É tenso!"13

3

Durante nossa entrevista Mateus conta que, ao ver os clipes dos seus artistas favoritos - Mc Daleste e Nêgo do Borel -, ele imaginava e queria estar no lugar onde eles estavam e levar a vida como a deles. E quando questionei sobre a importância de fazer um clipe ou de tirar fotos que simulassem esta realidade, ele respondeu: "eu fico doido para estar ali no lugar dele, entendeu? Tipo, ser visto ali por todo mundo. E todo mundo olhar e falar "pode crer, o moleque tem talento". No momento para mim eu vou estar, posso não estar para o mundo, mas para mim eu vou estar". Percebe-se então que Mateus formava-se e dava sentido à sua persona, Mc Ts, neste jogo de espelhos e nestas possibilidades de simulacros criados no cotidiano da contemporaneidade. A partir destes atravessamentos da sociedade e das poéticas do consumo, expressas nas músicas funk, em especial, mas também nos diferentes espaços e meios de comunicação do mundo contemporâneo, que o jovem arregimentava os signos que the convêm.

Estes estratagemas, segundo Seixas (2012), dizem respeito à capacidade performativa e os processos formativos e de subjetivação do indivíduo concebidos de

11 É necessário lembrar que o trabalho na construção civil, muita das vezes, é temporário e sem vínculos empregatícios. Mateus, não possui formação na área, tampouco conhecimentos que permitam uma certa permanência no posto de trabalho ou que o identifique com profissional da construção civil. Por isso, digo que este "jovem trabalhador da construção civil” é também um personagem.

12 "Molhado" é uma expressão usada para dizer de lugares ou situações difíceis e desagradáveis. Esta fala referia-se ao emprego de venda de abacaxi em uma cidade próxima a Uberlândia.

13 XAVIER, Mateus (MC TS). É o fluxo. Entrevistador: João Augusto Neves; Roberto Camargos. Uberlândia: Centelhafilmes, Agosto de 2014. Entrevista concedida para o documentário "É o fluxo".

Periferia, v.11, n. 1, p. 260-278, jan./abr. 2019 

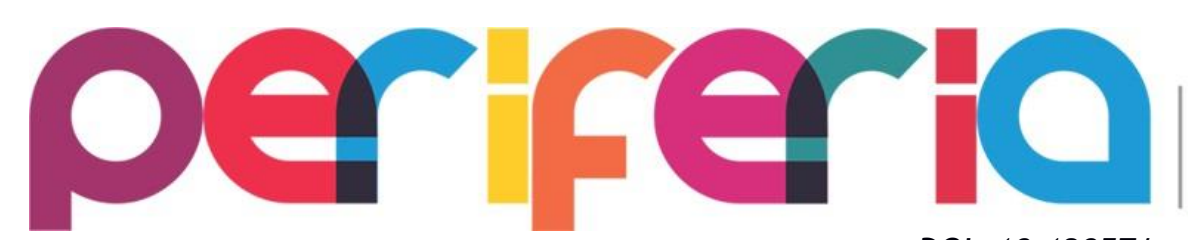

forma relacional, múltipla e multifacetada os quais são inerentes ao sujeito moderno, pois, conforme anota a historiadora,

o indivíduo se subjetiva na relação com os outros e consigo mesmo (jogos de alteridade, processos de identificação formativos do Eu) e, sobretudo, na medida em que potencializa suas possibilidades (in-finitas?) de desdobramentos, de ao mesmo tempo achar-se e perder-se em um jogo que acontece em espaços diversificados constituídos pelas dimensões do público, do privado e do íntimo. Esses complexos territórios que atravessam (cujas fronteiras são instáveis e permeáveis) são os mesmos que ele percorre, sem cessar, ao subjetivar-se. (SEIXAS, 2012, p. 285)

É preciso considerar, como observa diferentes autores, que este processo de subjetivação ganha intensas e perversas colorações no desenrolar do século XX e XXI, o que acaba impactando de forma singular na vida destes jovens pobres, moradores das periferias urbanas. Considerando que "nosso ser se constitui, por assim dizer, no ponto de interseção de si mesmo com uma esfera de exigência estrangeira" (SIMMEL, 2014, p. 156) que não está fora de nós e, tampouco, é estranha a nós, pode-se dizer que os fluxos e as efemeridades sensoriais da sociedade de consumo - potencializados pelas tecnologias digitais - criam situações de des-subjetivação, fragmentação e desengajamento do sujeito. Se o indivíduo contemporâneo forma-se "em pegar aqui e ali elementos diversos para produzir alguma coisa", ele acaba tornando-se, nessa sociedade que privilegia o consumo, um sujeito que vive "fazendo colagens, sua individualidade é [portanto] um patchwork de colagens" (CASTORIADIS, 2002, p. 156.) esvaziadas e que tendem à negação de sentidos. As consequências dessa crise de nosso tempo podem ser trágicas, pois

a transformação nas maneiras de sentir e de perceber são acompanhadas de uma mudança da personalidade contemporânea. As sociedades de consumo impõem um movimento incessante e uma atividade contínua, intensa, em que a precipitação, o frenesi e a urgência emperram a capacidade de julgar e promovem a superficialidade tanto em relação aos bens culturais quanto nas relações entre os indivíduos. (HAROCHE, 2008, p. 212)

Corroborando com essa tese, "a realidade (social e psíquica) do Eu e da subjetividade, quando experimentados como um "entre conglomerado," 

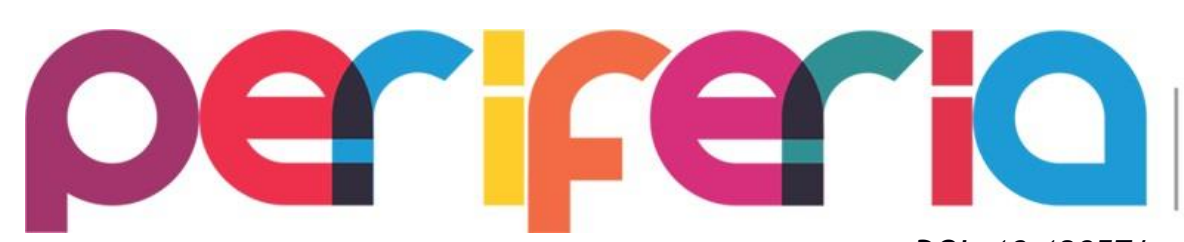

EDUCAÇÃO

CULTURA

\& COMUNICAÇÃO

DOI: $10.12957 /$ periferia.2019.30975

[potencializados pela valorização da ética do consumo], leva a um medo específico (...) - o medo de encarar o terror da ubiquidade" (SEIXAS, 2012, p.293). Estar em todos os lugares ao mesmo tempo, pode significar estar em lugar algum. $\mathrm{Na}$ sociedade contemporânea somos incitados a estar permanentemente conectados virtualmente a partir dos dispositivos de consumo e produção em massa das tecnologias digitais, no entanto, não somos capazes de dominar tais dispositivos devido sua efemeridade, flexibilidade, liquidez, enfim, tudo que conforma este fluxo informativo e produtivo - cada dia nos tornamos mais pacíficos e incapazes de compreender e dar sentido aos objetos e sujeitos que nos rodeia.

Walter Benjamin (1994), no início do século XX dirá que os indivíduos modernos, pobres de experiências, "nem sempre eles são ignorantes ou inexperientes. Muitas vezes, podemos afirmar o posto: eles "devoram" tudo, a "cultura" e os "homens", e ficaram saciados e exaustos." E seguido deste acumulo de tudo, de querer estar em tudo e em todos os lugares ele se cansa e "ao cansaço segue-se o sonho, e não é raro que o sonho compense a tristeza e o desânimo do dia, realizando a existência inteiramente simples e absolutamente grandiosa que não pode ser realizada durante o dia, por falta de forças" (BENJAMIN, 1994, p.118). Verifico, a partir deste texto, que a situação se agravou nos dias atuais. Os indivíduos, inseridos na sociedade de consumo operada em larga escala pelas tecnologias digitais, na sua gana de devorar tudo, não usa nada, vive e se realiza no sonho de ter tudo (ou nada?).

Seguindo essas premissas, Agamben diz que perdemos a capacidade de profanar, ou melhor, trazer para o uso comum o que foi sacralizado pela religião capitalista. ${ }^{14}$ Assim, "o que não pode ser usado acaba como tal, entregue ao consumo [imediato] ou à exibição [efêmera e] espetacular" (AGAMBEN, 2007, p.71). Nesse sentido, como reflete Seixas,

14 A concepção "O capitalismo como religião" foi trabalhada por Benjamin (2013), pois ele via que mais do que a secularização da fé protestante, como entendia Weber, o capitalismo se formula a partir de seu culto. Ele afirma que o "capitalismo é uma religião puramente cultural, talvez até a mais extremada que já existiu." Ver: BENJAMIN, Walter. O capitalismo como religião. In: LOWY, Michale (Org.). Walter Benjamin: O Capitalismo como religião. São Paulo: Boitempo, 2013. p.21.

Periferia, v. 11, n. 1, p. 260-278, jan./abr. 2019 


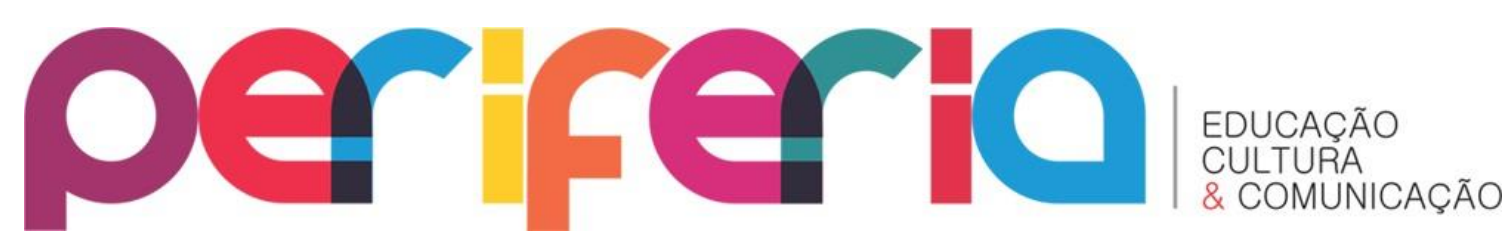

DOI: 10.12957/periferia.2019.30975

enuncia-se, parece-me, o desafio (misto de fascinação e temor “constelações afetivas” emblemáticas da modernidade) lançado pelo processo de des-subjetivação contemporâneo, com sua miríade de identidades e personas, potencializadas com os recursos tecnológicos da informática e do mundo virtual criado pelas webs e seus dispositivos. (SEIXAS, 2012, p.294)

O que verificamos no caso deste jovem morador da periferia de Uberlândia, que expressa sentimentos e experiências comuns a tanto outros jovens pobres de vários pontos do país, é uma profunda incapacidade de compreender os dispositivos que o agenciam, associado com a dificuldade de compreensão de sua formação enquanto indivíduo. Ou pior, estamos diante de um agravamento da situação que Benjamin (1994) já havia anunciado quando discute a pobreza de experiência. Suas reflexões revelam a impossibilidade de olharmos para trás ou mesmo compreendermos os sentimentos que participam do fazer humano, pois "abandonamos um depois da outra todas as peças do patrimônio humano, tivemos que empenhá-las muitas vezes a um centésimo do seu valor para recebermos em troca a moeda miúda do "atual”" (BENJAMIN, 1994, p.119).

Mateus, expressa este sentimento da necessária atualização constante. Ao reportar-se ao Mc "Novinho da Suzi ${ }^{15}$, que tinha na época milhões de acesso na internet, ele conta que: "TS também sonha em ter o mesmo sucesso". ${ }^{16}$ Ser "atual" significa, portanto, publicar fotos ou vídeos constantemente, consumir e ser consumido a cada instante, estar sintonizado com a voracidade dos movimentos das redes sociais.

Os ídolos do funk nos quais Mateus se inspirava também lançavam mão de subterfúgios técnicos e poéticos da atualidade para acessarem a sociedade do consumo e estarem sempre atualizados. Nos videoclipes e nas músicas do funk ostentação, por exemplo, os artistas - que são em sua maioria jovens da periferia brincavam com a realidade e inventavam um novo mundo a partir do sonho do consumo. Em uma entrevista para o site FilmMaker, Kondzilla, produtor de

15 Mc Novinho da Suzi, é um artista que canta música funk e na época da escrita deste texto contava com vários acessos nos seus vídeos do Youtube e muitos seguidores na sua página do Facebook, podendo ostentar-se como um dos ícones do movimento Funk Ostentação.

16 XAVIER, Mateus (MC TS). É o fluxo. Entrevistador: João Augusto Neves; Roberto Camargos. Uberlândia: Centelhafilmes, Agosto de 2014. Entrevista concedida para o documentário "É o fluxo".

Periferia, v. 11, n. 1, p. 260-278, jan./abr. 2019 


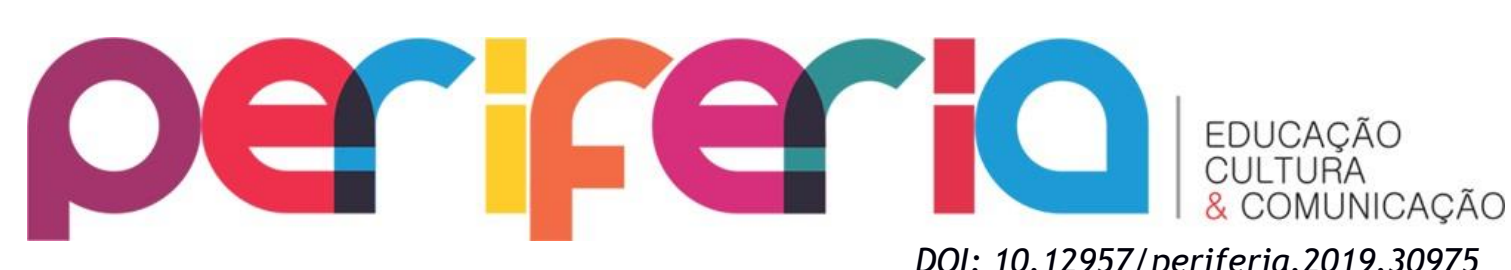

videoclipes de funk, expôs que a função do vídeo além de retratar a música cantada cumpria também o papel de "registrar essa fantasia". ${ }^{17} \mathrm{Em}$ outra reportagem o produtor reafirmava que apedar de "nem tudo o que é mostrado seja verdadeiro. Os artistas são personagens, estão vendendo um sonho ao público." 18 Ao (re)produzirem constantemente sonhos eles buscam uma "existência cheia de milagres" (BENJAMIN, 1994, p. 118), o que significa, conforme anota Simmel ao analisar a vida mental nas metrópoles regidas por relações essencialmente monetárias,

do ponto de vista da história da cultura, isto é apenas um fenômeno particular do crescimento dos conteúdos culturais em um solo no qual são estimulados e acolhidos por outras forças e outras finalidades que não as culturais e no qual com frequência inevitavelmente produzem flores estéreis. (SIMMEL, 2014, p. 159)

As experiências de Mateus, como a de outros jovens da periferia, mostram que vivemos em uma sociedade em que "tudo basta em si mesmo" (IBID, p. 119). Tanto nos videoclipes dos músicos de renome da cena funk ostentação quanto nas composições das músicas dos jovens das periferias essa questão fica evidente, como é possível notar na letra a seguir:

Olha o Fumaça passando de nave,

Camisa da Hero postarge,

Bridger estampado no pé e a bermuda da Ed Hardy.

Nosso bonde é fechado, onde nóis chega para tudo.

Zé povinho fica puto e nos olha como vagabundo.

Vem! Vem colar com nóis que nossa firma está podendo.

Está bandidagem monstra, os moleque tem talento.

Tem! Tem a LandRover, a Megane e a Mil e Cem.

Quando chega no baile apavorando de Citroen.

Porta-malas cheio de malote, de notas de cem,

Vem com nóis que é suíte, vem com nóis que hoje tem.

O mesmo se evidencia em outra composição:

17 Ver: MORI, Letícia. Conheça Kondzila, o diretor por trás dos principais clipes de funk ostentação. Folha de São Paulo. São Paulo, p. 1-4. 02 fev. 2014. Disponível em: <http://www1.folha.uol.com.br/saopaulo/2014/02/1405368-conheca-kondzilla-o-diretor-por-trasdos-principais-clipes-de-funk -ostentacao.shtml>. Acesso em: 10 set. 2014.

18 FILMMAKER. KondZilla: 0 Rei dos vídeoclipes. 2012. Disponível em: <http://hdslr.com.br/category/noticias/entrevistas>. Acesso em: 20 jul. 2014. Grifo meu.

Periferia, v.11, n.1, p. 260-278, jan./abr. 2019 


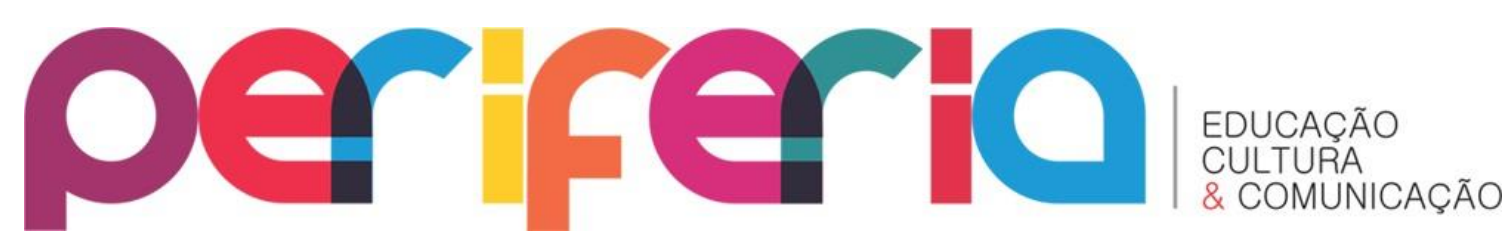

Sou TS tô chavante,

DOI: $10.12957 /$ periferia.2019.30975

com cordão brilhante e a Ferrari no rasante.

2one2 vai bem distante, mas é assim que é.

Chego nos baile com cinco mulher,

Eu peço, elas fazem tudo que eu quiser.

Minha ostentação é o que elas quer. ${ }^{19}$

Em ambas as músicas, a primeira de autoria de Mc Fumaça e a outra do seu amigo TS (Mateus), os compositores evidenciam os sonhos, as angustias e as forças esterilizantes que mobilizam os jovens da periferia de Uberlândia, a exemplo de tantos outros que participam dos "rolezinhos" nos shoppings, dos fluxos de bailes funk, das páginas do Facebook, enfim, de toda uma geração que se perde entre as poéticas do consumo da sociedade contemporânea. Os jovens Mc's priorizam em suas músicas, imagens das marcas de grifes, carros sofisticados e performances do poder, para dizer quem são e quais os elementos que os formam. A música narra a vida e os desejos provocados entre estes objetos de consumo, mas ao finalizar o canto tudo se esfumaça. Por um instante os Mc's se transformavam em jovens da periferia que andavam de "nave" e consumiam as famosas marcas de roupas e calçados para dar sentido a seu EU. $O$ tempo do instante, que deveria se multiplicar por todo o dia destes jovens, estava expresso na sua linguagem, gestualidade e sentimentos que conformavam sua subjetividade. Mesmo que essas práticas e produções tensionem o regime de classes do sistema capitalista, este culto ao tempo instantâneo e ao consumismo, ao mesmo tempo em que alimenta a sociedade de mercado torna-se a avalanche perversa da exclusão social que se volta contra eles próprios.

\section{4}

As reflexões de Walter Benjamin, contidas em "O capitalismo como religião", fonte de inspiração para muitas ideias presentes neste artigo, traz à tona interessantes questões sobre a essência do capitalismo. Ao problematizar aspectos relacionados à modernidade, Benjamin entende que o capitalismo deve ser interpretado como uma espécie de religião, pois o mesmo "está essencialmente a

19 Músicas registradas em: Documentário É o fluxo. Uberlândia, Centelhafilmes, Agosto de 2014. A primeira composição não tem registro ou titulação, já a segunda recebe o nome de "Nóis é mil grau" do Mc TS.

Periferia, v. 11, n. 1, p. 260-278, jan./abr. 2019 


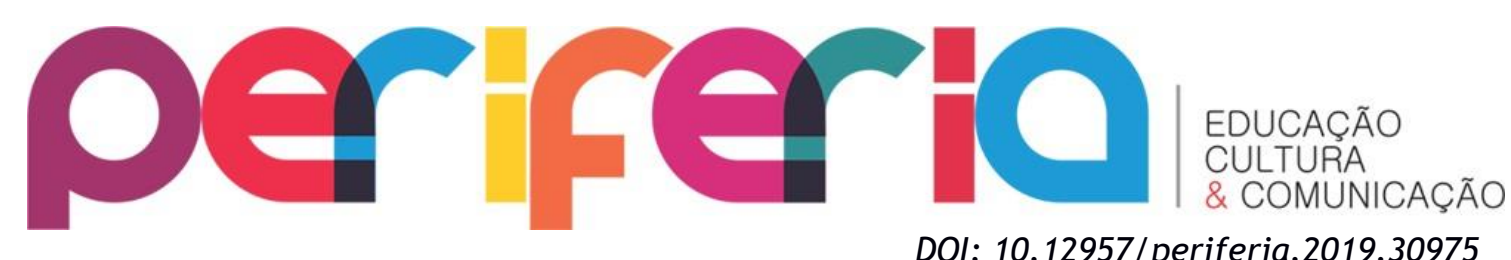

serviço da resolução das mesmas preocupações, aflições e inquietações a que outrora as assim chamadas religiões quiseram oferecer resposta" (BENJAMIN, 2013, p. 21). Desta forma, trazendo essa reflexão para o contexto aqui enfocado, os sentimentos e as subjetividades presentes entre os jovens moradores das periferias urbanas, como é o caso de Mateus, constituíam-se no interior de um universo no qual o culto à "religião capitalista" ganhava forma no ato do consumo. Dito de outra forma, o que se pretende afirmar é que estes sujeitos acionavam em seus vídeos, músicas e nas imagens construídas para suas diferentes personas, dispositivos perversos da sociedade capitalista. Ao buscarem conectar-se ao mundo globalizado adotavam um vocabulário simbólico do luxo e da ostentação, o qual, no limite, pode significar a suspensão da sua capacidade de se engajar em movimentos que proporcionem a transformação de sua condição social. Como diz Haroche, o que está em curso nas sociedades contemporâneas é

um profundo processo de transformação que, ao provocar o esvaziamento da capacidade de atenção, indissociável da reflexão, leva ao empobrecimento da interioridade e, diversas vezes, retira da pessoa seus atributos mais fundamentais. (HAROCHE, 2008, p. 212)

Essas reflexões possibilitam aproximar Haroche das preocupações levantadas por Benjamin, sobre a pobreza de experiência do homem no início do século XX, bem como, das críticas desenvolvidas por Hannah Arendt, em seus trabalhos sobre a suspensão da consciência e a banalização do mal. Ambos os autores destacam as posturas assumidas pelo indivíduo moderno e as consequências destas escolhas. Essa ausência de profundidade, em que nossas experiências são mediadas pelo consumo, cria um cenário no qual prevalecem a incapacidade de sentir-se e de identificar a si mesmo e aos outros, (con)formando subjetividades sujeitadas e isoladas. Portanto, o preço da atualização em ritmo acelerado tem sido muito alto para esses jovens moradores das periferias urbanas. Diferentemente daqueles que nasceram em condições financeiras favoráveis, ou, dos poucos que conseguiram ascender no meio artístico do funk, alcançando prestígio e até notoriedade na mídia, para a maioria a sobrevivência os remete para uma realidade de desemprego, expedientes, subemprego, e até mesmo de criminalidade. Nesse ambiente, os apelos à ostentação, 


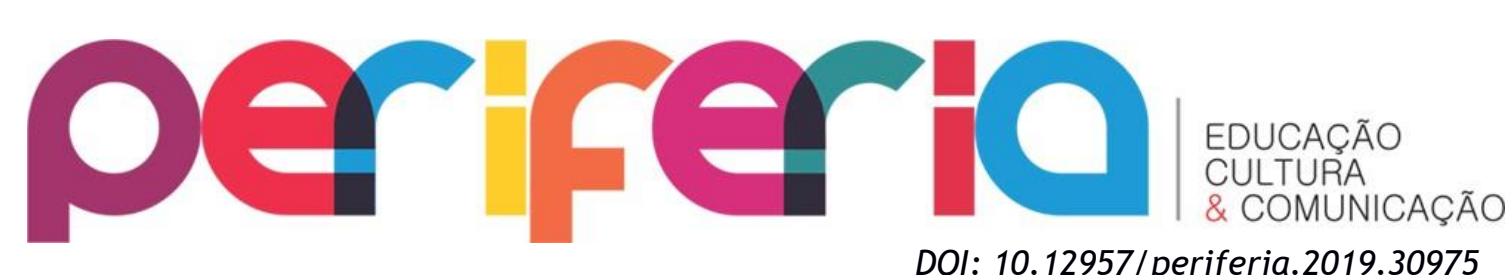

alimentando uma cultura do consumismo praticamente impossível de ser alcançada, não passa de um subterfúgio perverso. Se, no campo simbólico da performatividade isso pode acalentar o sonho do pertencimento e da ascensão ao "todo", na prática, o saldo alcançado pode ter como resultado o "nada".

\section{REFERÊNCIAS}

AGAMBEN, Giorgio. Profanações. São Paulo: Boitempo, 2007.

ASTROS E ÍDOLOS: MC Guimê o rei do Funk Ostentação. Bauru, São Paulo: Alto Astral, v. 65, n. 12, 2014.

BAUMAN, Zygmunt. Danos colaterais: desigualdades sociais numa era gobal. Rio de Janeiro: Zahar, 2013.

BENJAMIN, Walter. O capitalismo como religião. In: LOWY, Michale (Org.). Walter Benjamin: O Capitalismo como religião. São Paulo: Boitempo, 2013

. Experiência e pobreza. In: BENJAMIN, Walter. Obras escolhidas: Magia e técnica, arte e política: ensaios sobre literatura e história da cultura. São Paulo: Brasiliense, 1994.

CASTORIADIS, Cornelius. As encruzilhadas do labirinto. Vol. IV. São Paulo: Paz e Terra, 2002.

CALDEIRA, Teresa Pires do Rio Caldeira. Qual a novidade dos rolezinhos? Espaço público, desigualdade e mudança em São Paulo. Novos Estudos. CEBRAP, n 98 . pp. 13-20, Março 2014.

GEORG, Simmel. O conceito e a tragédia da cultura. Crítica Cultural - Critic, Palhoça, SC, v. 9, n.1, p. 145-162, jan./jun.2014. p. 156. Tradução: SANTOS, Antônio Carlos.

Documentário É o fluxo. Uberlândia, Centelhafilmes, Agosto de 2014.

FILMMAKER. KondZilla: O Rei dos vídeoclipes. 2012. Disponível em: <http://hdslr.com.br/category/noticias/entrevistas>. Acesso em: 20 jul. 214

HAROCHE, Claudine. A condição sensível: formas e maneiras de sentir no Ocidente. Rio de Janeiro: Contra Capa, 2008.

KUCHLER, Adriana. Amigo de Neymar, Mc Guimê fala de maconha, ostentação e seu hino da copa. Folha de São Paulo. São Paulo, p. 1-10. 29 jun. 2014. Disponível 


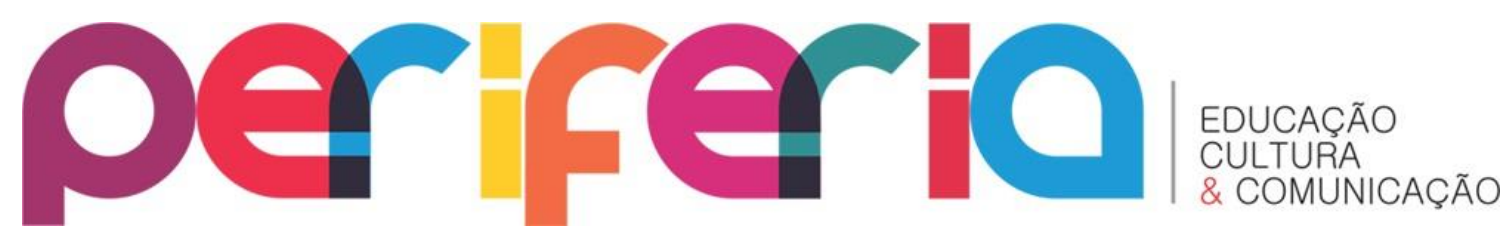

DOI: $10.12957 /$ periferia.2019.30975

em:<http: / tools. folha.com.br/print?url=http: / /www1.folha.uol.com.br/serafina/ 2014/06/1476758-amigo-de-neymar-mc-guime-fala-de-maconha-ostentacao-e-seuhino-dacopa. shtml\&site=emcimadahora $>$.

LEMOS, Ronaldo. Abre alas para o funk ostentação. 2012. Disponível em: <http://www1. folha.uol.com.br/colunas/ronaldolemos/1198020-abre-alas-para-ofunk-ostentacao.shtml>. Acesso em: 20 jul. 2014.

MARTINS, Mateus Xavier. Documentário É o fluxo. Uberlândia, Centelhafilmes, Agosto de 2014. Entrevista a João Augusto Neves e Roberto Camargos.

MORI, Letícia. Conheça Kondzila, o diretor por trás dos principais clipes de funk ostentação. Folha de São Paulo. São Paulo, p. 1-4. 02 fev. 2014. Disponível em: <http://www1.folha.uol.com.br/saopaulo/2014/02/1405368-conheca-kondzilla-odiretor-por-tras-dos-principais-clipes-de-funk -ostentacao.shtml>. Acesso em: 10 set. 2014.

SEIXAS, Jacy Alves de. Linguagens da perplexidade: personas, infinitos desdobramentos (três narrativas, três tempos). In: SEIXAS, Jacy Alves de; CERASOLI, Jossianne; NAXARA, Márcia (Orgs.). Tramas do Político: Linguagens, formas, jogos. Uberlândia: Edufu, 2012. 